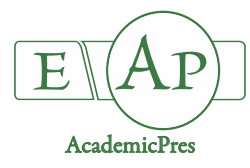

\title{
Carbon-Nitrogen Metabolic Responses and Adaptive Strategies to Low-Nitrogen Stress in Glycine soja
}

\author{
He WANG ${ }^{1, a}$, Rui GUO ${ }^{2, b *}$, Yongjun $\mathrm{HU}^{1, \mathrm{c}}$, Defu HAN ${ }^{1 *}$ \\ ${ }^{1}$ Chang Chun Normal University, School of Life Sciences, 130024, Changchun, China; \\ 1822416631@qq.com; huyongiun68@sina.com; handf67@163.com \\ ${ }^{2}$ Chinese Academy of Agricultural Sciences, Institute of Environment and Sustainable Development in Agriculture, Key Laboratory of Dryland \\ Agriculture, 100081,Beijing, China; guor219@yahoo.com \\ $a, b, c$ These authors have contributed equally to this work
}

\begin{abstract}
Nitrogen $(\mathrm{N})$ is an essential mineral nutrient for plant growth and development. Wild soybean (Glycine soja), which has many superior traits, is an important germplasm resource and is also an excellent experimental material for researching the mechanisms of low-N tolerance. In this study, the physiological differences between common wild soybean (W1) and low-N tolerant wild soybean (W2) among growth characteristics, photosynthetic carbon (C) metabolism, N metabolism and C-N metabolic-coupling relationship were investigated, and the mechanism of low- $\mathrm{N}$ tolerance of wild soybean was explained at three different levels of low-N stress. Both W1 and W2 showed some resistance to low-level N stress. However, W2 could withstand the damage by increasing the root length and root-shoot ratio under high-level stress conditions. Moreover, when resisting low-N stress, W2 maintained a stable photosynthetic rate and coordinated ion balance to maintain required nutrient levels. W2 also tolerated low $\mathrm{N}$ by coordinating the $\mathrm{C}-\mathrm{N}$ metabolic balance through the accumulation of soluble sugars to provide energy and $\mathrm{C}$ skeletons for $\mathrm{N}$ metabolism and through enhanced $\mathrm{N}$ metabolic enzyme activities and soluble protein accumulation levels to supply the enzyme proteins and photosynthetic pigments for $\mathrm{C}$ metabolism. The current results provide a physiological methodology and theoretical basis for protecting wild soybean germplasm resources and improving cultivated soybean.
\end{abstract}

Keywords: carbon-nitrogen mechanism; Glycine soja; low-nitrogen; physiology; stress

\section{Introduction}

Carbon $(\mathrm{C})$ and nitrogen $(\mathrm{N})$ are essential for plants to perform their routine and fundamental cellular activities during development (Sun et al., 2013); therefore, adequate supplies are critical for plant growth and stress responses. $\mathrm{C}$ and $\mathrm{N}$ metabolism are basic processes of plant physiology. The intensity and dynamic changes directly affect the formation of photosynthetic products, transformation, mineral nutrient absorption and protein synthesis, which significantly impacts the growth and development of plants (Yu et al., 2015). N, as the primary nutrient factor and a main component of plant cells, is a major limiting factor affecting crop $\mathrm{C}$ and $\mathrm{N}$ metabolism (Huang et al., 2015).

The amount of $\mathrm{N}$ required by Glycine soja is high, and the $\mathrm{N}$ provided by the symbiotic rhizobia is insufficient to support the plant's demands for N (Ciocco et al., 2011). Low $N$ stress can affect the normal physiological and metabolic activities, limit the growth of seedlings, and reduce the biomass accumulation of soybean plants (Shah,
2017). Wild soybean can oppose the damage caused by saline-alkali stress by adjusting the ion content distribution using high tolerance- and low absorption-related mechanisms (Jiao et al., 2018). The photosynthetic physiological characteristics of cultivated and wild soybean are affected significantly under low $\mathrm{N}$ stress. Wild soybean can increase the accumulation of carotenoids (Cars) to resist coercive damage (Li et al., 2018). However, there are few reports on the C-N metabolism pathways and adaptive mechanisms of $\mathrm{N}$ tolerance among different types of wild soybeans.

Wild soybean is a leguminous soybean species that is an annual herb (Hao et al., 2016). It is the wild relative of cultivated soybean and has a high protein content, strong stress tolerance and high propagative coefficient (Phang et al., 2008). Wild soybean is the most effective resource for broadening the genetic basis of cultivated soybean breeding (Farag et al., 2012; Xue et al., 2014). In this study, we used common and low-N-tolerant wild soybean as experimental materials. We compared the effects of three different levels of low- $\mathrm{N}$ stress on growth, photosynthetic parameters and

Received: 14 May 2019. Received in revised form: 01 Nov 2019. Accepted: 21 Nov 2019. Published online: 28 Nov 2019. 
1216

enzyme activities related to $\mathrm{N}$ metabolism between the two wild soybean varieties in a sand culture experiment. By analyzing the response and adaptation processes of C-N metabolic-coupling relationship with low- $\mathrm{N}$ stress, the physiological mechanism of $\mathrm{N}$ tolerance in wild soybean was revealed. This study provides physiological references for the conservation and utilization of wild soybean germplasm resources by adapting the basic metabolism and physiology of wild soybean during environmental selection.

\section{Materials and Methods}

Plant materials and growth conditions

The seeds of wild soybean ('Huinan 06116', W1) and low N- tolerant wild soybean ('Tongyu 06311', W2), were provided by the Jilin Changchun Crop Germplasm Introduction and Breeding Center. The seedlings were grown in sand culture using cleaned and sieved river sand. Soybean seeds were arranged in 14-cm diameter pots with a bottom hole (2-cm diameter), with three seeds of a single line per pot. During the experiment, temperatures were 18.5 $\pm 1.5^{\circ} \mathrm{C}$ and $26 \pm 2{ }^{\circ} \mathrm{C}$ during the night and day, respectively, and the relative humidity was $60 \pm 5 \%$.

\section{Stress treatments}

The low $\mathrm{N}$ treatment was initiated after the plants grew their third leaves. In the low-N-treated group, W1 and W2 seeds were placed in three types of stress solutions: one halfstrength (N1), one fourth-strength (N2) and one eighthstrength (N3) modified Hoagland's solution (Table 1). Calcium $(\mathrm{Ca})$ and potassium $(\mathrm{K})$ were supplied by $\mathrm{CaCl}_{2} \cdot 2 \mathrm{H}_{2} \mathrm{O}$ and $\mathrm{KCl}$, respectively, at equivalent concentrations in low-N Hoagland's solution for 2 weeks. In the check control (CK), both types of wild soybean seedlings were cultivated under normal conditions $(1 \times$ Hoagland's solution). W1 and W2 were each divided into four groups: control, and N1, N2 and N3 treated. Each group consisted of eight pots: four pots for measuring growth parameters and photosynthesis, and four pots for ion content and enzyme activity analyses.

\section{Measurement of growth indices}

After the wild soybean plants were harvested, plant heights, root lengths, aboveground fresh weights (Up FWs), underground FWs (Root FWs), aboveground dry weights (Up DWs) and underground dry weights (Root DWs) were measured (Shao et al., 2016).

\section{Measurement of ion contents}

Dry $0.05 \mathrm{~g}$ samples were treated with $4 \mathrm{~mL}$ of deionized water at $100{ }^{\circ} \mathrm{C}$ for $40 \mathrm{~min}$ and then centrifuged at 3,000 g for $15 \mathrm{~min}$. The supernatants were collected and the methods were repeated twice, with extracts queued up to 15 $\mathrm{mL}$. Unified supernatants were used to determine $\mathrm{SO}_{4}{ }^{2-}$, nitrate $\left(\mathrm{NO}_{3}^{-}\right), \mathrm{H}_{2} \mathrm{PO}_{4}^{-}$and $\mathrm{C}_{2} \mathrm{O}_{4}^{-}$concentrations using ion chromatography (DX-300 ion chromatographic system, AS4A-SC chromatographic column, CDM-II electrical conductivity detector, mobile phase: $\mathrm{Na}_{2} \mathrm{CO}_{3} / \mathrm{NaHCO}_{3}=$ 1.7/1.8 mM; Dionex, Sunnyvale, CA, USA). An atomic absorption spectrophotometer (Super 990F, Beijing Purkinje General Instrument Co. Ltd. Beijing, China) was used to determine the concentrations of $\mathrm{Zn}^{2+}, \mathrm{Mn}^{2+}, \mathrm{K}^{+}$, $\mathrm{Ca}^{2+}, \mathrm{Mg}^{2+}, \mathrm{Fe}^{2+}, \mathrm{B}^{3+}$ and $\mathrm{Cu}^{2+}$.

\section{Measurement of photosynthetic pigments}

Two weeks after the stress treatment, the photosynthetic gas exchange parameters were determined using the fully expanded functional blade at the third upper node in four plants per plot receiving the same treatment. The gas exchange parameters, including leaf net photosynthetic rate $\left(P_{\mathrm{N}}\right)$, stomatal conductance $\left(g_{\mathrm{s}}\right)$, ratio of sub-stomatal to atmospheric $\mathrm{CO}_{2}$ concentrations and transpiration rate $(E)$, were determined using a LI-6400 portable openflow gas-exchange system (LI-COR, USA) at 11:00 AM. $P_{\mathrm{N}}, g_{s}, E$ and the ratio of sub-stomatal to atmospheric $\mathrm{CO}_{2}$ concentrations are presented in $\mu \mathrm{mol}$ $\mathrm{CO}_{2} \mathrm{~m}^{-2} \mathrm{~s}^{-1}$, mol m $\mathrm{m}^{-2} \mathrm{~s}^{-1}$, $\mu \mathrm{mol} \mathrm{H}_{2} \mathrm{O} \mathrm{m} \mathrm{m}^{-2}$ and $\mathrm{cm}^{3} \mathrm{~m}^{-3}$. Water use efficiency was calculated as the ratio of $P_{\mathrm{N}} / E$. The photosynthetically active radiation was $1,200 \pm 50 \mu \mathrm{mol}$ $\mathrm{m}^{-2} \mathrm{~s}^{-1}, \mathrm{CO}_{2}$ concentration was $380 \pm 5 \mathrm{~cm}^{3} \mathrm{~m}^{-3}$, and the air temperature and relative humidity were $24^{\circ} \mathrm{C}$ and $50 \%$. Gas exchange parameters were measured in fully expanded leaves. There were five replications for each measurement, using three leaves per pot, and three data points were recorded per leaf, for a total of 45 data points per treatment.

To extract the photosynthetic pigments, dried leaf samples $(30 \mathrm{mg})$ were dipped into $10 \mathrm{~mL}$ of an $80 \%$ acetone:anhydrous ethanol mixture $(1: 1)$ in darkness at room temperature until the leaves became white. Five pots were used to measure the photosynthetic pigment content, and the measurement was repeated three times per pot for a total of 15 data points per treatment. Spectrophotometric (SpectrUV-754, Shanghai Accurate Scientific Instrument Co.) determinations at 440, 645 and $663 \mathrm{~nm}$ for each sample were performed three times. The photosynthetic pigment content $\left(\mathrm{mg} \mathrm{g}^{-1}\right)$, including chlorophyll a $(C h l \mathrm{a})$, chlorophyll b $(C h l \mathrm{~b})$, chlorophyll a + chlorophyll b $[C h l$ (a + b)] and Car, was calculated (Holm, 1954; Jiao et al., 2018).

Determination of enzyme activity associated with $N$
metabolism
Nitrate reductase (NR) activity was determined according to the method described by Robin (1979). An extract of $0.1 \mathrm{~mL}$ was incubated in a reaction mixture containing $0.5 \mathrm{~mL}$ of $0.1-\mathrm{M}$ potassium phosphate buffer (pH 7.4), $0.1 \mathrm{~mL} 100 \mathrm{mM}$ EDTA, $0.1 \mathrm{~mL}$ of $0.15-\mathrm{mM}$ $\mathrm{NADH}$ and $0.1 \mathrm{~mL}$ of $0.1-\mathrm{M} \mathrm{KNO}_{3}$ at $30^{\circ} \mathrm{C}$ for $30 \mathrm{~min}$. The reaction was stopped by adding $0.1 \mathrm{~mL}$ of $1-\mathrm{M}$ zinc acetate. The absorbance of the supernatant was determined at $540 \mathrm{~nm}$ after diazotation with $1 \mathrm{~mL}$ of $5.8-\mathrm{mM}$ sulfanilamide in $1.5-\mathrm{N} \mathrm{HCl}$ and $1 \mathrm{~mL}$ of $0.8-\mathrm{mM} \mathrm{N}$ naphthyl-ethylenediamine dichloride. The glutamine synthase (GS) activity was measured according to $\mathrm{Yu}$ and Zhang (2012). Fresh plant leaves were cut into pieces and homogenized in 50-mM Tris- $\mathrm{HCl}(\mathrm{pH} \mathrm{8.0)}$ containing 2$\mathrm{mM} \mathrm{MgSO}_{4}, 2-\mathrm{mM} \mathrm{DTT}$ and $0.4-\mathrm{M}$ sucrose in a precooled mortar in an ice bath. The homogenate was centrifuged at $12,000 \mathrm{~g}$ at $48{ }^{\circ} \mathrm{C}$ for $20 \mathrm{~min}$. Next, $1.0 \mathrm{~mL}$ crude enzyme solution was added to $1.6 \mathrm{~mL}$ reaction mixture (0.6 mL 0.25-M imidazole- $\mathrm{HCl}$ buffer, $0.4 \mathrm{~mL} 0.3$ $\mathrm{M}$ sodium hydrogen glutamate, $0.4 \mathrm{~mL}$ 0.03-M ATP-Na 
and $\left.0.2 \mathrm{~mL} 0.5-\mathrm{M} \mathrm{MgSO}_{4}\right)$. The mixture was incubated at $258^{\circ} \mathrm{C}$ for $5 \mathrm{~min}, 0.2 \mathrm{~mL}$ hydroxylamine hydrochloride was subsequently added, and the mixture was incubated for 15 min. Next, $0.8 \mathrm{~mL} \mathrm{FeCl}$ solution (0.37- $\mathrm{M} \mathrm{FeCl}_{3}, 0.2-\mathrm{M}$ trichloroacetic acid and $0.6-\mathrm{M} \mathrm{HCl}$ ) was added to terminate the reaction. After centrifugation at 4,000 $\mathrm{g}$ at 48 ${ }^{\circ} \mathrm{C}$ for $10 \mathrm{~min}$, the absorbance of the supernatant was recorded at $540 \mathrm{~nm}$. GDH activity was analyzed using the method described by Gupta (2012). The extraction buffer ( $\mathrm{pH}$ 7.9) consisted of 0.05-M imidazole and 5-mM DTT. Leaves $\left(1 \mathrm{~g}\right.$ ) were ground in liquid $\mathrm{N}_{2}$ in a chilled mortar and pestle and were centrifuged at $12,000 \mathrm{~g}$ for $40 \mathrm{~min}$ at 4 ${ }^{\circ} \mathrm{C}$. The supernatant was collected and stored at $-20^{\circ} \mathrm{C}$. The assays were carried out using the continuous spectrophotometric rate determination method. The GOT and GPT activities were determined according to the method of Zhang and Qu (2004). Fresh leaves (0.5 g) were cut into pieces and homogenized in 50-mM Tris- $\mathrm{HCl}(\mathrm{pH}$ 7.2) in a precooled mortar in an ice bath. The homogenate was centrifuged at $12,000 \mathrm{~g}$ at $48{ }^{\circ} \mathrm{C}$ for $20 \mathrm{~min}$. The supernatant was added to a GOT reaction solution $(3 \mathrm{mg}$
$\mathrm{mL}^{-1}$ of $\mathrm{NADH}, 0.2-\mathrm{M}$ L-aspartate, 2,000 U malate dehydrogenase and 50-mM a-ketoglutaric acid), and the absorbance of the mixture at $340 \mathrm{~nm}$ was recorded to measure the GOT activity. The supernatant was added to a GPT reaction solution $\left(3 \mathrm{mg} \mathrm{mL} \mathrm{mL}^{-1}\right.$ of $\mathrm{NADH}, 0.2-\mathrm{M} \mathrm{L}$ alanine, 2,000 $\mathrm{U}$ lactate dehydrogenase and $50-\mathrm{mM}$ aketoglutaric acid), and the absorbance of the mixture at 340 $\mathrm{nm}$ was recorded to measure the GPT activity. The soluble protein contents of leaves were estimated at $595 \mathrm{~nm}$ using the Coomassie brilliant blue reagent by following the procedure described by Lowry (1951) and was expressed in $\mathrm{mg} \mathrm{g}^{-1} \mathrm{FW}$.

\section{Statistical analyses}

Statistical analyses of the data were performed using the statistical program SPSS 13.0 (SPSS, Chicago, IL, USA). All the data are presented as averages of five biological replicates with standard errors (SEs). Curves in figures were determined using the regression curve-fitting function of Sigma Plot 12.0 (Jandel, Erkrath, Germany) and Visio 2016 (Visio for Windows).

Table 1. Formulation of the nutrient- and stress-treatment solutions for plant growth

\begin{tabular}{ccccc}
\hline Reagent name & $\mathrm{CK}\left(\mathrm{mmol} \mathrm{L}^{-1}\right)$ & $\mathrm{N} 1\left(\mathrm{mmol} \mathrm{L}^{-1}\right)$ & $\mathrm{N} 2\left(\mathrm{mmol} \mathrm{L}^{-1}\right)$ & $\mathrm{N}^{\left(\mathrm{mmol} \mathrm{L}^{-1}\right)}$ \\
\hline $\mathrm{Ca}\left(\mathrm{NO}_{3}\right)_{2} \cdot 4 \mathrm{H}_{2} \mathrm{O}$ & 34.776 & 17.388 & 8.695 & 4.347 \\
$\mathrm{MgSO}_{4} \cdot 7 \mathrm{H}_{2} \mathrm{O}$ & 25.049 & 25.049 & 25.049 & 25.049 \\
$\mathrm{KH}_{2} \mathrm{PO}_{4}$ & 20.001 & 20.001 & 20.001 & 20.001 \\
$\mathrm{KNO}_{3}$ & 50.009 & 25.005 & 12.502 & 6.251 \\
$\mathrm{Na}_{-}-\mathrm{EDTA}_{4}$ & 2.366 & 2.366 & 2.366 & 2.366 \\
$\mathrm{FeSO}_{4} \cdot 7 \mathrm{H}_{2} \mathrm{O}$ & 1.379 & 1.379 & 1.379 & 1.379 \\
$\mathrm{H}_{3} \mathrm{BO}_{3}$ & 4.628 & 4.628 & 4.628 & 4.628 \\
$\mathrm{MnSO}_{4}$ & 0.663 & 0.663 & 0.663 & 0.663 \\
$\mathrm{CuSO}_{4} \cdot 5 \mathrm{H}_{2} \mathrm{O}$ & 0.032 & 0.032 & 0.032 & 0.032 \\
$\mathrm{ZnSO}_{4} \cdot 7 \mathrm{H}_{2} \mathrm{O}$ & 0.077 & 0.077 & 0.077 & 0.077 \\
$\mathrm{H}_{2} \mathrm{MoO}_{4}$ & 0.056 & 0.056 & 0.056 & 0.056 \\
$\mathrm{CaCl}_{2} \cdot 2 \mathrm{H}_{2} \mathrm{O}$ & 0 & 13.034 & 26.068 & 52.136 \\
$\mathrm{KCl}$ & 0 & 18.753 & 37.505 & 75.01 \\
\hline
\end{tabular}

\section{Results}

Changes in plant growth parameters under low- $N$ stress

There were differences in growth performances between W1 and W2 under different low- $\mathrm{N}$ stress conditions (Fig. 1). Compared with the $\mathrm{CK}$, the low-N stress level resulted in decreased Plant heights, Up FWs, Root FWs, Up DWs and Root DWs in W1. The decreases were more prominent under the most severe low-N stress compared with the low and medium levels of low-N stress. However, there was no significant effect on the growth parameters of W2 under low-N stress conditions, just a slight decrease in the parameters under the most severe low- $\mathrm{N}$ stress level. In addition, the root length of W2 increased significantly as the stress became more severe, while there was no change in these parameters in W1.

\section{Ion accumulation}

With an increase in the intensity of the low- $\mathrm{N}$ stress, there were obvious differences between the ion contents of the roots and leaves of the two wild soybean varieties (Table 2). Under the lowest low- $\mathrm{N}$ stress level, the $\mathrm{K}^{+}, \mathrm{Fe}^{2+}, \mathrm{B}^{3+}$,
$\mathrm{C}_{2} \mathrm{O}_{4}^{-}, \mathrm{H}_{2} \mathrm{PO}_{4}^{-}$and $\mathrm{Mg}^{2+}$ contents in W2 roots increased, but there were no significant changes in W1 roots compared with the $\mathrm{CK}$. Under the medium stress level, the $\mathrm{NO}_{3}^{-}, \mathrm{Cu}^{2+}, \mathrm{Zn}^{2+}, \mathrm{Mn}^{2+}, \mathrm{SO}_{4}^{2-}$ and $\mathrm{Ca}^{2+}$ contents in the $\mathrm{W} 2$ roots remained stable, while the levels in the $\mathrm{W} 1$ roots decreased more at the medium and high levels compared with the lowest stress level. Under the high-level stress, the ion content in W1 roots decreased significantly, while it remained high in $\mathrm{W} 2$ roots. Under low- $\mathrm{N}$ stress, the $\mathrm{H}_{2} \mathrm{PO}_{4}^{-}, \mathrm{Mg}^{2+}, \mathrm{K}^{+}, \mathrm{Fe}^{2+}, \mathrm{B}^{3+}, \mathrm{C}_{2} \mathrm{O}_{4}^{-}, \mathrm{NO}_{3}{ }^{-}, \mathrm{Cu}^{2+}$ and $\mathrm{Zn}^{2+}$ contents decreased in the leaves of both varieties, with greater reductions in W1 than in W2.

\section{Photosynthetic parameters}

Under low-N stress, the photosynthetic physiological parameters of both genotypes were affected, and the $P_{\mathrm{N}}$ and $C h l(a+b)$ content decreased significantly (Fig. 2). With an increase in the intensity of low-N stress, the $P_{\mathrm{N}}, g_{\mathrm{s}}$ and water use efficiency values decreased more in W1 than in W2. E decreased in W2 but increased in W1. Compared with the $\mathrm{CK}$, the photosynthetic pigment contents decreased significantly in W1 but the decrease in W2 was not obvious 


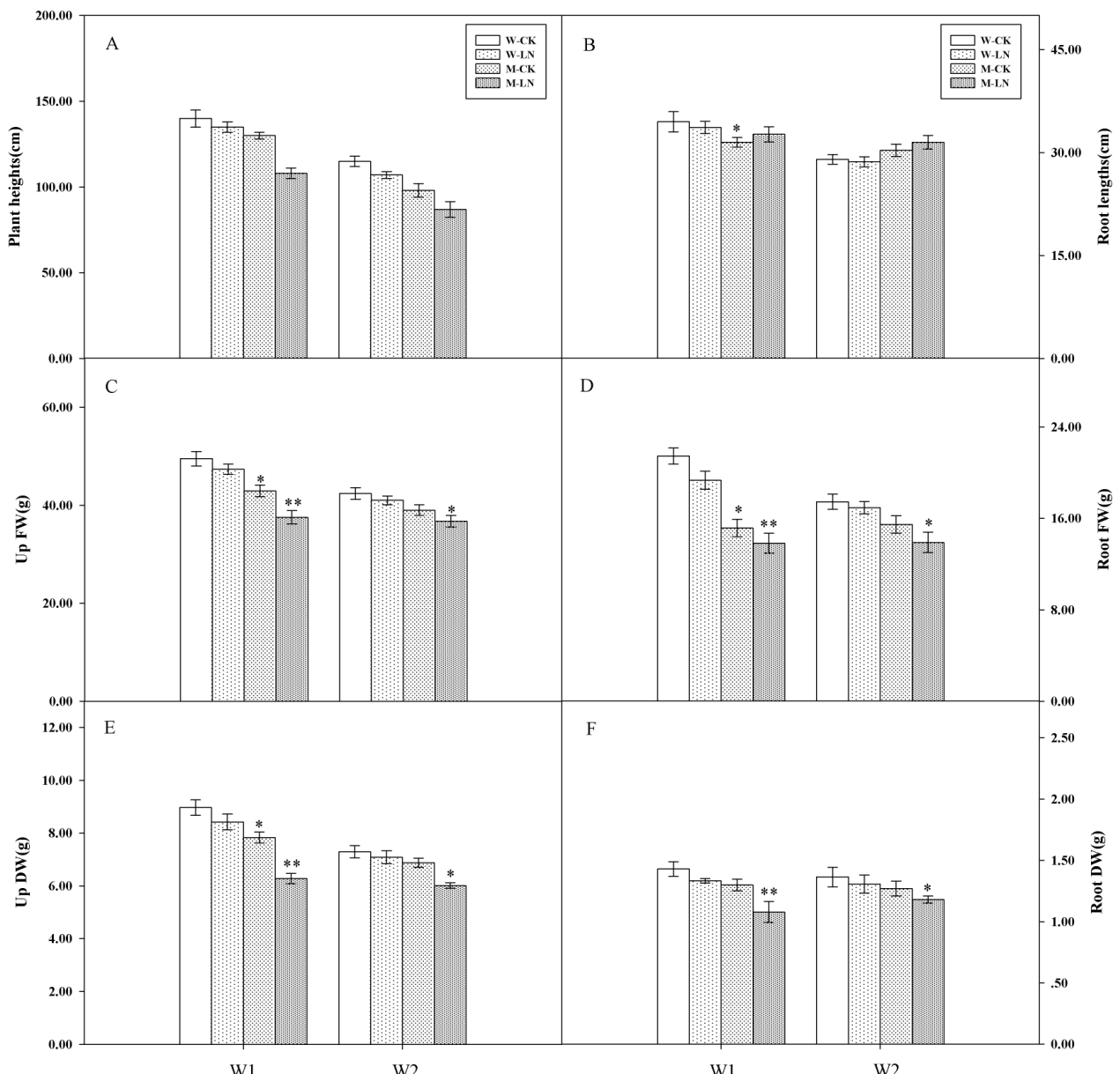

Fig. 1. The changes in plant growth parameters in the two wild soybean under control and LN-stress conditions

Note: (A) Plant heights; (B) Root lengths; (C) aboveground FW (Up FW); (D) underground fresh weight (Root FW); (E) aboveground dry weight (Up DW:); (F) underground dry weight (Root DW). ${ }^{*}$ and ${ }^{* *}$ indicate significant $(\mathrm{P}<0.05)$ and highly significant $(\mathrm{P}<0.01)$ differences, respectively

Table 2. Ion contents in roots of two wild soybean seedlings under control and low nitrogen stress conditions

\begin{tabular}{|c|c|c|c|c|c|c|c|c|c|c|c|c|c|c|}
\hline \multirow{3}{*}{ Samples } & \multicolumn{8}{|c|}{ Relative concentration } & \multirow{2}{*}{\multicolumn{2}{|c|}{$\begin{array}{l}\text { Fold changes } \\
\log _{2}(\mathrm{~N} / \mathrm{CK})\end{array}$}} & \multirow{2}{*}{\multicolumn{2}{|c|}{$\begin{array}{l}\text { Fold changes } \\
\log _{2}(\mathrm{~N} 2 / \mathrm{CK})\end{array}$}} & \multirow{2}{*}{\multicolumn{2}{|c|}{$\begin{array}{l}\text { Fold changes } \\
\log _{2}(\mathrm{~N} 3 / \mathrm{CK})\end{array}$}} \\
\hline & \multicolumn{4}{|c|}{ W1 } & \multicolumn{4}{|c|}{ W2 } & & & & & & \\
\hline & CK & N1 & $\mathrm{N} 2$ & N3 & CK & N1 & $\mathrm{N} 2$ & N3 & W1 & $\mathrm{W} 2$ & W1 & W2 & W1 & W2 \\
\hline $\mathrm{Mn}^{2+}$ & 0.03 & 0.02 & 0.05 & 0.03 & 0.03 & 0.03 & 0.04 & 0.05 & -0.26 & 0.05 & $0.94^{*}$ & $0.27^{*}$ & $0.19^{*}$ & $0.59^{*}$ \\
\hline $\mathrm{B}^{3+}$ & 0.07 & 0.11 & 0.14 & 0.12 & 0.03 & 0.09 & 0.11 & 0.12 & 0.74 & $1.43^{*}$ & $1.02^{*}$ & 1.66 & $0.26^{*}$ & $0.54^{*}$ \\
\hline $\mathrm{Cu}^{2+}$ & 0.44 & 0.34 & 0.32 & 0.28 & 0.34 & 0.33 & 0.33 & 0.31 & -0.38 & -0.02 & -0.47 & -0.06 & -0.20 & -0.05 \\
\hline $\mathrm{Fe}^{2+}$ & 0.06 & 0.07 & 0.08 & 0.06 & 0.04 & 0.06 & 0.07 & 0.07 & 0.28 & $0.46^{*}$ & 0.50 & 0.73 & 0.01 & $0.24^{*}$ \\
\hline $\mathrm{Zn}^{2+}$ & 0.02 & 0.02 & 0.01 & 0.00 & 0.01 & 0.01 & 0.01 & 0.01 & $-0.43^{*}$ & -0.21 & -0.74 & -0.49 & -0.78 & -0.42 \\
\hline $\mathrm{K}^{+}$ & 233.48 & 221.00 & 294.92 & 254.35 & 178.90 & 234.25 & 270.69 & 281.98 & -0.08 & $0.39^{*}$ & 0.34 & 0.60 & 0.04 & $0.20^{*}$ \\
\hline $\mathrm{Ca}^{2+}$ & 21.00 & 15.14 & 13.85 & 15.75 & 10.34 & 19.10 & 17.99 & 23.05 & -0.47 & $0.89^{*}$ & -0.60 & $0.80^{*}$ & -0.12 & $0.35^{*}$ \\
\hline $\mathrm{Mg}^{2+}$ & 32.13 & 21.38 & 21.61 & 23.53 & 15.19 & 21.68 & 24.26 & 26.66 & -0.59 & $0.51^{*}$ & -0.57 & $0.67^{*}$ & -0.14 & $0.24^{*}$ \\
\hline $\mathrm{Cl}^{-}$ & 3.39 & 8.81 & 7.82 & 8.48 & 2.26 & 4.73 & 5.02 & 8.20 & $1.38^{*}$ & $1.06^{*}$ & $1.21^{*}$ & $1.15^{*}$ & $1.32^{*}$ & $1.86^{*}$ \\
\hline $\mathrm{NO}_{3}{ }^{-}$ & 3.75 & 1.03 & 0.24 & 0.36 & 3.41 & 2.22 & 1.01 & 1.38 & $-1.86^{*}$ & -0.62 & $-3.99^{*}$ & $-1.75^{*}$ & $-3.38^{*}$ & $-1.30^{*}$ \\
\hline $\mathrm{H}_{2} \mathrm{PO}_{4}^{-}$ & 9.79 & 13.11 & 15.41 & 14.36 & 8.20 & 10.09 & 11.15 & 12.10 & 0.42 & 0.30 & 0.66 & 0.44 & 0.55 & 0.56 \\
\hline $\mathrm{SO}_{4}^{2-}$ & 6.84 & 13.12 & 16.08 & 13.50 & 4.66 & 10.96 & 13.29 & 11.42 & 0.94 & 1.23 & 1.23 & 1.51 & 0.98 & 1.29 \\
\hline $\mathrm{C}_{2} \mathrm{O}_{4}^{-}$ & 1.58 & 1.74 & 1.83 & 1.78 & 1.59 & 1.66 & 1.82 & 1.97 & 0.14 & 0.07 & 0.21 & 0.20 & 0.17 & $0.31^{*}$ \\
\hline
\end{tabular}

Note: The ion contents are the mean of data from four biological replicates; the fold changes were calculated using the formula $\log 2($ nitrogen/control); W1, common wild soybean; W2, low nitrogen-tolerant wild soybean; CK, control treatment; N1, low-intensity low nitrogen stress stress; N2, medium-intensity low nitrogen stress; N3, high-intensity low nitrogen stress;

*significant $(\mathrm{P}<0.05)$ differences, respectively. 
under the low-level stress. With the increase in stress intensity, the $C h l \mathrm{a}, C h l \mathrm{~b}$ and $C h l(\mathrm{a}+\mathrm{b})$ contents in the leaves of W1 seedlings decreased more than in W2. In particular at the N3 level, the contents in W1 decreased by $53.32 \%, 55.53 \%$ and $50.08 \%$, respectively, while those in W2 decreased by $39.41 \%, 45.82 \%$ and $28.51 \%$, respectively, compared with the CK. It is worth noting that the Car and soluble sugar contents showed an opposite trend, increasing under low-N stress in W2 but decreasing in W1.

\section{Enzyme activities of $N$ metabolism}

There were significant differences in the activity levels of
$\mathrm{N}$ metabolism-related enzymes and the soluble protein content between W1 and W2 leaves at different levels of low-N stress (Table 3). Compared with the CK, NR and GDH showed no significant changes in either W1and W2 under the low-level stress, but they decreased under the medium-level stress, especially in W1. With an increase in the intensity of the low-N stress, GS decreased in W1 but increased in W2. Meanwhile, the soluble sugar content increased in W2 but did not significantly change in W1. Glutamine oxoglutarate aminotransferase (GOGAT) and GPT decreased in W1 but remained high in W2 as the intensity of the low-N stress increased.

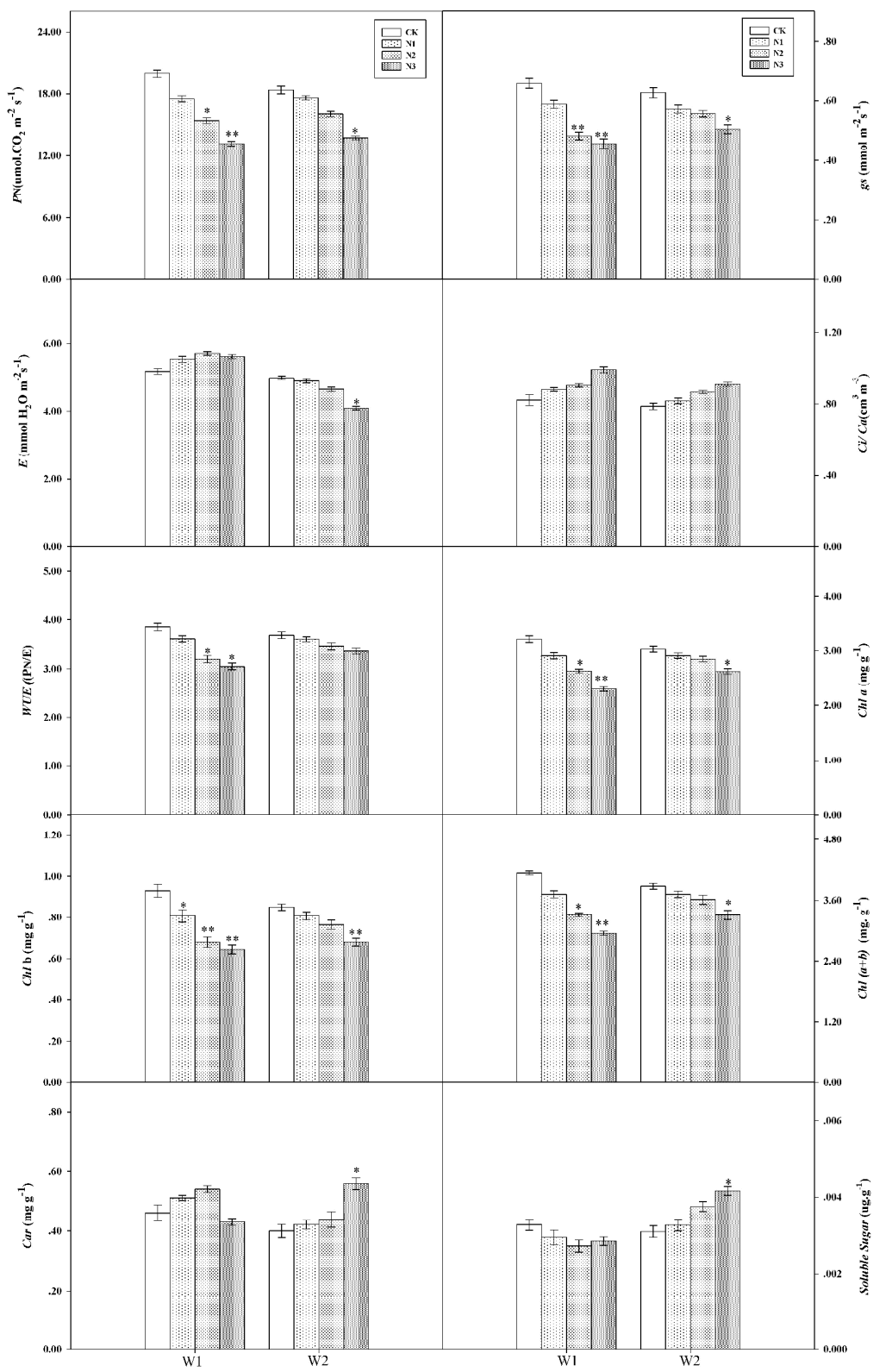

Fig. 2. The changes in photosynthetic characteristics of the two wild soybean under CK and LN stress

Note: (A) Net photosynthetic rate $\left(p_{\mathrm{N}}\right)$; (B) stomatal conductance $\left(g_{\mathrm{s}}\right)$; (C) transpiration rate $(E)$; (D) ratio of sub-stomatal to atmospheric $\mathrm{CO}_{2}$ concentrations $\left(C_{\mathrm{i}} / C_{\mathrm{a}}\right) ;(\mathrm{E})$ ratio of $p_{\mathrm{N}} / E(W U E) ;(\mathrm{F})$ chlorophyll a $(C h l \mathrm{a}) ;(\mathrm{G})$ chlorophyll b $(C h l \mathrm{~b}) ;(\mathrm{H})$ chlorophyll $\mathrm{a}+\mathrm{b}(\mathrm{Chl}(\mathrm{a}+\mathrm{b}))$; (I) carotenoid (Car); (J) Soluble Sugar. ${ }^{*}$ and ${ }^{* *}$ indicate significant $(\mathrm{P}<0.05)$ and highly significant $(\mathrm{P}<0.01)$ differences, respectively 
Table 3. The changes in enzyme activities of nitrogen metabolism in the two wild soybean under control and LN-stress conditions

\begin{tabular}{|c|c|c|c|c|c|c|c|c|c|c|c|c|c|c|}
\hline \multirow{3}{*}{ Samples } & \multicolumn{8}{|c|}{ Relative concentration } & \multirow{2}{*}{\multicolumn{2}{|c|}{$\begin{array}{l}\text { Fold changes } \\
\log _{2}(\mathrm{~N} 1 / \mathrm{CK})\end{array}$}} & \multirow{2}{*}{\multicolumn{2}{|c|}{$\begin{array}{l}\text { Fold changes } \\
\log _{2}(\mathrm{~N} 2 / \mathrm{CK})\end{array}$}} & \multirow{2}{*}{\multicolumn{2}{|c|}{$\begin{array}{l}\text { Fold changes } \\
\log _{2}(\mathrm{~N} / \mathrm{CK})\end{array}$}} \\
\hline & \multicolumn{4}{|c|}{ W1 } & \multicolumn{4}{|c|}{ W2 } & & & & & & \\
\hline & CK & N1 & $\mathrm{N} 2$ & N3 & CK & N1 & $\mathrm{N} 2$ & N3 & W1 & W2 & W1 & W2 & W1 & W2 \\
\hline NR & 2.72 & 2.61 & 2.27 & 2.11 & 3.53 & 3.15 & 2.94 & 2.88 & -0.06 & -0.26 & $-0.37^{*}$ & -0.16 & $-0.26^{*}$ & $-0.29^{*}$ \\
\hline GS & 1.56 & 1.52 & 1.44 & 1.31 & 1.48 & 1.51 & 1.58 & 1.60 & -0.04 & -0.12 & $-0.26^{*}$ & 0.03 & $0.09^{* *}$ & 0.12 \\
\hline GOGAT & 12.17 & 11.07 & 9.10 & 8.67 & 13.23 & 12.20 & 11.70 & 10.67 & -0.14 & -0.42 & $-0.49^{*}$ & -0.12 & $-0.18^{*}$ & $-0.31^{*}$ \\
\hline GPT & 0.10 & 0.09 & 0.08 & 0.04 & 0.11 & 0.09 & 0.08 & 0.07 & -0.14 & -0.23 & -1.18 & -0.24 & $-0.31^{*}$ & -0.59 \\
\hline GOT & 0.05 & 0.06 & 0.05 & 0.04 & 0.04 & 0.07 & 0.07 & 0.06 & $0.29^{* *}$ & $0.09^{* *}$ & -0.03 & $0.58^{* *}$ & 0.70 & $0.57^{*}$ \\
\hline GDH & 144.83 & 131.00 & 105.83 & 91.00 & 100.50 & 95.13 & 90.83 & 86.67 & -0.14 & -0.45 & $-0.67^{*}$ & $-0.08^{*}$ & $-0.15^{* *}$ & $-0.21^{*}$ \\
\hline $\begin{array}{l}\text { Soluble } \\
\text { protein }\end{array}$ & 33.70 & 31.29 & 28.47 & 27.64 & 42.67 & 43.55 & 44.81 & 46.39 & -0.11 & -0.24 & $-0.29^{*}$ & $0.03^{*}$ & $0.07^{* *}$ & $0.12^{*}$ \\
\hline
\end{tabular}

Note: NR, nitrate reductase; GS, glutamine synthetase; GOGAT, glutamate synthase; GPT, glutamic-pyruvic transaminase; GOT, glutamic-oxaloacetic transaminase; GDH, glutamate dehydrogenase ; Soluble protein. ${ }^{*}$ and ${ }^{* *}$ indicate significant $(\mathrm{P}<0.05)$ and highly significant $(\mathrm{P}<0.01)$ differences, respectively.

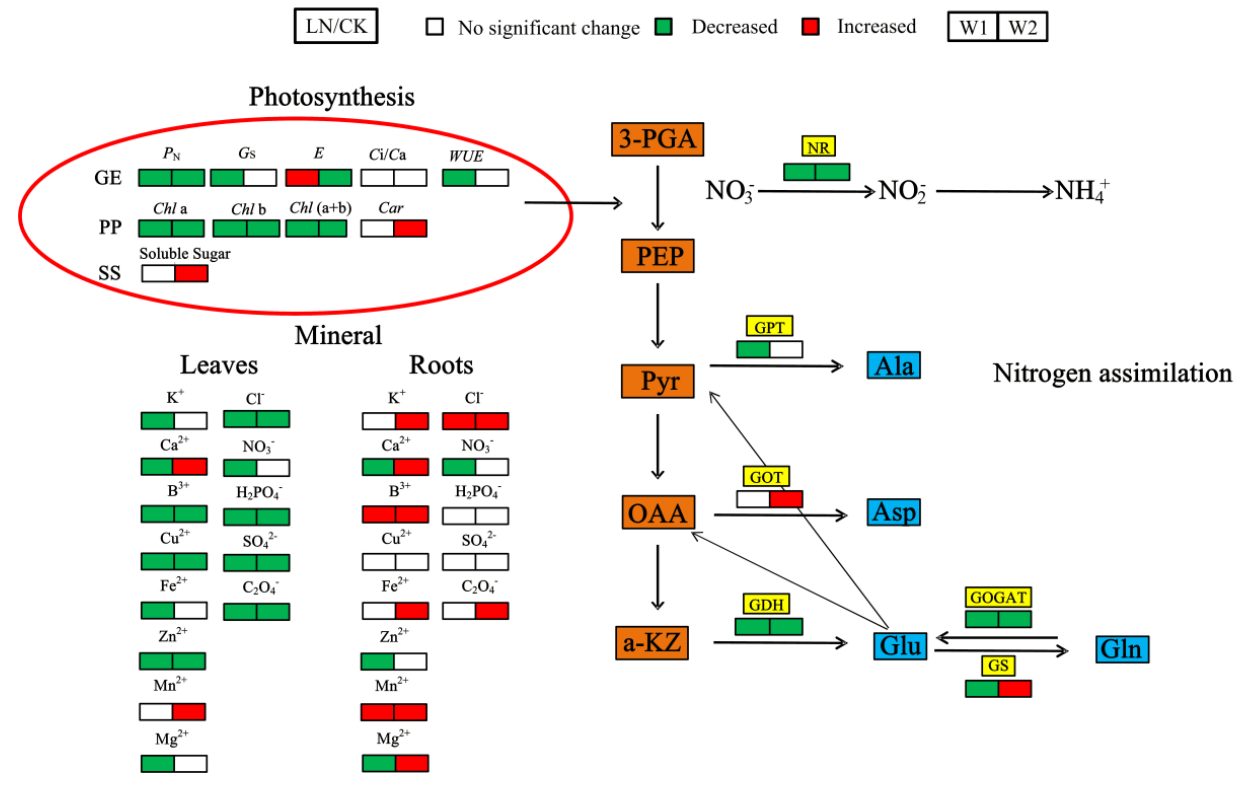

Fig. 3. Simplified integrative model for carbon and nitrogen metabolic pathways

Note: This scheme summarizes the main interaction points between carbon and nitrogen metabolism. a-KZ, a-ketoglutaric acid; Ala, alanine; Asp, aspartic acid; Glu, glutamic acid; Gln, glutamine; OAA, oxaloacetate; PEP, phosphoenolpyruvate; Pry, pyruvic acid

\section{Discussion}

$\mathrm{N}$ is an essential element for plant growth and development. An $\mathrm{N}$ deficiency can rapidly inhibit plant growth and biomass accumulation, especially plant height and dry matter, respectively (Osborne, 2006). There were significant differences in growth and biomass accumulation between two different types of wild soybean under different low-N stress levels. The growth inhibition was clearly greater in W1 than in W2. Roots are a vital organ system of plants owing to their involvement in water and nutrient acquisition, storage functions, and metabolite synthesis and accumulation. In addition, roots have formed a series of mechanisms to resist adverse environmental conditions (Quain, 2015). W2 was better able to adapt to the low-N stress, as reflected by the significant increase of root length and R/S (Fig. 1).

The absorption of nutrients by plants can be inhibited by low-N stress. The lack of any nutrient element changes plant metabolism (Amiour et al., 2012; Takehisa, 2013). Maintaining ion nutrient homeostasis under low- $\mathrm{N}$ stress is an important low- $\mathrm{N}$ tolerance strategy for plants (Prasanna, 2013). P is an important substrate for energy metabolism and biofilm biosynthesis, and it participates in regulating electron transport and the oxidative phosphorylation of mitochondria (Oosterhuis, 2012). In this study, $\mathrm{H}_{2} \mathrm{PO}_{4}^{-}$ gradually accumulated in the W2 root system as the intensity of the low- $\mathrm{N}$ stress increased, which allowed chloroplast energy transfer and photosynthetic phosphorylation in W2, which promoted the following metabolic pathway: $\mathrm{ADP}+\mathrm{Pi}+\mathrm{NADP}^{+}+\mathrm{H}_{2} \mathrm{O} \rightarrow \mathrm{APT}+$ $\mathrm{NADPH}+\mathrm{O}_{2}$.

Meanwhile, APT and NADPH provide more energy for $\mathrm{C}$ assimilation in W2 (Ng'etich, 2013). $\mathrm{Mg}^{2+}$ can activate RuBP carboxylase to promote $\mathrm{CO}_{2}$ assimilation and cause GS to contribute to the transformation of ammonium 
$\left(\mathrm{NH}_{4}^{+}\right)$to amino acid. Iron can stimulate the participation of carbohydrates in photosynthesis and $\mathrm{N}$ fixation, leading to the absorption of iron by plant roots in the form of $\mathrm{Fe}^{2+}$ (Mohammed, 2011; Akay, 2012). $\mathrm{K}^{+}$has a positive effect on enzyme activation and protein synthesis in plants. $\mathrm{B}$ is an essential component and is related to the stability of plant cell wall structures, carbohydrate transport and NR activity, which contributes to an enhancement of the $\mathrm{N}$ fixation capacity (Alemán, 2011). One low-N tolerance strategy maintained by W2 was a high absorptive ability for ions, including $\mathrm{Mg}^{2+}, \mathrm{Fe}^{2+}, \mathrm{B}^{3+}$ and $\mathrm{K}^{+}$under $\mathrm{N} 1$ and $\mathrm{N} 2$ conditions. Simultaneously, there was no significant change under N 3 conditions, indicating that W2 could adjust the mineral ion nutrient balance to reduce the damage caused by low-N stress. Accumulations of $\mathrm{SO}_{4}^{2-}, \mathrm{Ca}^{2+}$ and $\mathrm{Mn}^{2+}$ were maintained in W2 leaves to ensure a sufficient nutrient balance at all low- $\mathrm{N}$ stress levels, which may be an effective way of adapting to soil nutrient deficiencies.

$\mathrm{N}$ metabolic processes and regulation are crucial for plant-stress resistance. The key enzyme activity of $\mathrm{N}$ metabolism is an important index in determining the relationship between stress and $\mathrm{N}$ assimilation, which connects $\mathrm{C}$ and $\mathrm{N}$ metabolism in a plant and influences the whole $\mathrm{N}$ metabolic process (Chen, 2017). Plants can promote $\mathrm{N}$ assimilation to reduce the damage from low- $\mathrm{N}$ stress by self-regulating the activities of $\mathrm{N}$-metabolic enzymes and increasing the soluble protein content (Zhao, 2018). The enzymes of $N$ metabolism are synergetic. NR is $\mathrm{a} \mathrm{NO}_{3}{ }^{-}$-inducible and rate-limiting enzyme in the process of $\mathrm{NO}_{3}{ }^{-}$assimilation (Kaiser and Huber, 2001). $\mathrm{NO}_{3}{ }^{-}$is reduced to $\mathrm{NO}_{2}^{-}$by $\mathrm{NR}$, and then to $\mathrm{NH}_{4}^{+}$by nitrite reductase (Ren, 2014). $\mathrm{NH}_{4}+$ is synthesized to glutamine (Gln) by GS after entering the $\mathrm{N}$-assimilation pathway. Then, Gln and a-oxoglutarate (a-KZ) were transformed into two molecules of glutamate (Glu) by GOGAT. One could be used as the substrate of GS, while the other could be converted to synthesize proteins, nucleic acids and other nitrogenous compounds. This pathway is the GS/GOGAT cycle in which GS and GOGAT work at the same time assimilating $\mathrm{NH}_{4}^{+}$(Chang, 2017). a-KZ is reduced and ammoniated to Glu by GDH. GOT and GPT are transaminases. The former catalyzes the transamination between Glu and pyruvate (Pyr), and the latter between Glu and oxaloacetate (OAA), which play important roles in the redistribution of C-N metabolism among plant cell cytoplasm and other compartments (Pang, 2015; Jia-Ling, 2015). In our study, N-deficiency reduced the activities of NR, GOGAT and GPT, but they remained essentially constant in W2 at the N3 level. GS accumulated gradually as the intensity of the low-N stress increased. With high NR, GS/GOGAT and GDH activities, W2 could effectively hasten the conversion of $\mathrm{NH}_{4}^{+}$and generate more Glu as the substrate for transamination reactions. High GOT and GPT activities occurred in W2 under low$\mathrm{N}$ stress in this work, which increased the flow of $\mathrm{N}$ from amino and amide groups, both of which are essential for plant growth. Soluble protein accumulation increased in response to low-N stress (Fig. 3), which played a role in reducing water potential to maintain a water and nutrient balance. It also provides enzyme proteins that participate in various metabolic pathways for the rapid recovery from stress, ultimately improving plant growth and development (Ya-Wei, 2017).

Stress tolerance, which helps plant to survive under stressed conditions, inevitably depends on the endogenous C-N metabolism (Liu et al., 2014). C metabolism provides a C source and energy for $\mathrm{N}$ metabolism. Under low- $\mathrm{N}$ conditions, W2 can adjust leaf $g_{s}$ and $E$ to reduce water evaporation and avoid affecting photosynthesis. Additionally, W2 could adjust photosynthetic metabolism through compensative mechanisms that allowed the plants to adapt to low- $\mathrm{N}$ stress. Soluble sugar, a main product of $\mathrm{C}$ metabolism in plants, reflects the carbohydrate and energy levels in plants. The low$\mathrm{N}$ stress noticeably affected the accumulation of soluble sugar (Fig. 2). With the increased intensity of low-N stress, the soluble sugar content increased in W2 but decreased in W1. The accumulation of soluble sugar could enhance the osmotic potential and provide availability of energy and C skeletons for the N metabolism in W2 (Nunes-Nesi et al., 2010). Under low-N stress, W2 had a stable and sufficient photosynthetic assimilation ability to directly provide NADPH, Fdred and ATP for $\mathrm{NO}_{3}{ }^{-}, \mathrm{NO}_{2}{ }^{-}$and $\mathrm{NH}_{4}{ }^{+}$assimilation. $\mathrm{C}$ metabolism ensures that there is enough $\mathrm{C}$ diverted to produce $\mathrm{C}$ skeletons that are needed during the assimilation of $\mathrm{N}$.

In turn, $\mathrm{N}$ metabolic enzymes maintained high activity levels, which provided enzyme proteins and photosynthetic pigments for $\mathrm{C}$ metabolism. As shown in Fig. 3, phosphoenolpyruvate, generated from glycolysis, is converted to Pyr and OAA, respectively. OAA and Pyr enter the TCA cycle, producing energy and key $\mathrm{C}$ intermediates, including aKZ. NR and nitrite reductase reduce cellular $\mathrm{NO}_{3}{ }^{-}$into $\mathrm{NH}_{4}{ }^{+}$, which is then incorporated into $\mathrm{a}-\mathrm{KZ}$ to form Gln by the GS/GOGAT pathway or which directly interacts with a-KZ to form Glu by GDH. Glu and Gln further exchange amine to form other amino acids and amides. W2 can maintain a high total $\mathrm{C}$ level, adjust the ion and nutrient relationship and increase the $\mathrm{N}$-assimilation rate, to regulate the $\mathrm{C}-\mathrm{N}$ balance and avoid the harm caused by low- $\mathrm{N}$ stress.

\section{Conclusions}

Both W1 and W2 are wild soybeans with similar visual structures, but they adapt to adverse conditions differently by adjusting physiological characteristics and metabolic pathways. We demonstrated that both W1 and W2 showed certain resistance capabilities to a low intensity of low-N stress. As the intensity of low-N stress increased, W2's ability to survive was greater than that of W1 owing to physiological and metabolic plasticity strategies, including increasing root lengths that it employed. W2 had a less pronounced decrease in its photosynthetic rate and accumulated more Car and soluble sugar than W1. It also promoted $\mathrm{C}$ assimilation to provide more energy and $\mathrm{C}$ skeletons for $\mathrm{N}$ metabolism under low-N stress conditions. Additionally, W2 maintained greater $\mathrm{N}$-metabolic enzyme activity levels to ensure a photosynthetic pigment and enzyme protein supply for C metabolism, which maintained a $\mathrm{C}-\mathrm{N}$ assimilation balance that could alleviate the inhibition of plant growth caused by low-N stress. W2 also had strong ion absorption ability and could regulate the ion balance in root system to resist low-N stress. Our results provide an important theoretical basis for the protection, exploitation and utilization of wild soybean resources. 
1222

\section{Conflict of Interest}

The authors declare that there are no conflicts of interest related to this article.

\section{References}

Akay G, Burke DR (2012). Agro-process intensification through synthetic rhizosphere media for nitrogen fixation and yield enhancement in plants. American Journal of Agricultural and Biological Science $7(2): 150-172$

Alemán F, Nievescordones M, Martínez V, Rubio F (2011). Root k (+) acquisition in plants the Arabidopsis thaliana model.Plant and Cell Physiology 52(9):1603-1612.

Amiour N, Imbaud S, Cl Mao Ment G, Agier N, Zivy M, Valot B (2012). The use of metabolomics integrated with transcriptomic and proteomic studies for identifying key steps involved in the control of nitrogen metabolism in crops such as maize.Journal of Experimental Botany 63(14):5017.

Chang JF, Dong PF, Wang XI, Liu WL, Chaohai LI, University HA (2017). Effect of nitrogen application on carbon and nitrogen metabolism of different summer maize varieties. Scientia Agricultura Sinica 50(12):2282-2293.

Chen JK, Tan LT, Chun-Ming YU, Zhu AG, Ping C, Wang YZ (2017). Effects of different nitrogen levels on key enzyme activities associated with nitrogen metabolism of feed ramie. Acta Prataculturae Sinica 10:29.

Ciocco CD, Penón E, Coviella C, LópezS, Diaz-Zorita M, MomoF (2011). Nitrogen fixation by soybean in the pampas: relationship between yield and soil nitrogen balance. Agrochimica 55(6):1-10.

Duanmu HZ, Wang Y, Bai X, Cheng SF, Deyholos MK, Wong GKS, ... Zhu YM (2015). Wild soybean roots depend on specific transcription factors and oxidation reduction related genes in response to alkaline stress. Functional and Integrative Genomics 15(6):651-660.

Farag MA, Porzel A, Wessjohann LA (2012). Comparative metabolite profiling and fingerprinting of medicinal licorice roots using a multiplex approach of GC-MS, LC-MS and ID NMR techniques. Phytochemistry 76:60-72.

Gupta N, Gupta AK, Gaur VS, Kumar A (2012). Relationship of nitrogen use efficiency with the activities of enzymes involved in nitrogen uptake and assimilation of finger millet genotypes grown under different nitrogen inputs. The Scientific WorldJournal 10:625731.

Hao Q, Shang W, Zhang C, Chen H, Chen L, Yuan S (2016). Identification and comparative analysis of cbs domain-containing proteins in soybean (Glycinemax) and the primary function of gmcbs 21 in enhanced tolerance to low nitrogen stress. International Journal of Molecular Sciences 17(5):620.

Hashimoto H, Uragami C, Cogdell RJ (2016). Carotenoids and photosynthesis. In: Carotenoids in Nature.Springer, Cham pp111-139.

Holm G (1954). Chlorophyll mutation in barley. Acta Agriculturae Scandinavica 4(1):457-471.

Huang SJ, Chen S, Liang ZH, Zhang CM, Yan M, Chen JG (2015). Knockdown of the partner protein OsNAR2.1 for high-affinity nitrate transport represses lateral root formation in a nitrate-dependent manner.
Scientific Reports 5:18192.

Jiao Y, Bai Z, Xu J, Zhao M, Khan Y, Hu Y (2018). Metabolomics and its physiological regulation process reveal the salt-tolerant mechanism in Glycine soja seedling roots. Plant Physiology and Biochemistry 126:187196.

Ju X (2014). The concept and meanings of nitrogen fertilizer availability ratio-discussing misunderstanding of traditional nitrogen use efficiency. Acta PedologicaSinica 51(5):921-933.

Ju XT, Xing GX, Chen XP, Zhang SL, Zhang LJ, Liu XJ (2009). Reducing environmental risk by improving $\mathrm{N}$ management in intensive Chinese agricultural systems. Proceedings of the National Academy of Sciences 106(9):3041-3046.

Kaiser WM, Huber SC (2001). Post-translational regulation of nitrate reductase: mechanism, physiological relevance and environmental triggers. Journal of Experimental Botany 52(363):1981-1989.

Liu C, Wang Y, Pan K, Zhu T, Li W, Zhang L (2014). Carbon and nitrogen metabolism in leaves and roots of dwarf bamboo (Fargesia denudata Yi) subjected to drought for two consecutive years during sproutingperiod. Journal of Plant Growth Regulators 33(2):243-255.

Lowry OH, Brough NTR, Fair LA, Randall RJ (1951). Protein measurement with folin phenol reagent. The Journal of Biological Chemistry 193:265-275.

Mauromicale G, Ierna A, Marchese M (2006). Chlorophyll fluorescence and chlorophyll content in field-grown potato as affected by nitrogen supply, genotype, and plant age. Photosynthetica 44(1):76-82.

Li M, Xu J, Wang X, Fu H, Zhao M, Wang H, Shi L (2018). Photosynthetic characteristics and metabolic analyses of two soybean genotypes revealed adaptive strategies to low-nitrogen stress. Journal of Plant Physiology 229:132-141.

Mohammed AR, Tarpley L (2011). Morphological and physiological responses of nine southern US rice cultivars differing in their tolerance to enhanced ultraviolet-b radiation.Environmental and Experimental Botany 69(2):174-184.

Niyokuri OKAN, Rono JJ, Fashaho A, Ogweno JO (2013). Effect of different rates of nitrogen fertilizer on the growth and yield of zucchini (Cucurbita pepo cv. Diamant L.) hybrid F1 in Rwandan high altitude zone. International Journal of Agriculture \& CropSciences 5(1):5462.

Nunes-Nesi A, Fernie AR, Stitt M (2010). Metabolic and signalling aspects underpinning the regulation of plant carbon-nitrogen interactions. Molecular Plant3(6):973-996.

Oosterhuis DM, Zhou Z (2012). Physiological mechanism of nitrogen mediating cotton (Gossypium hirsutum L.) seedlings growth under water-stress conditions. American Journal of Plant Sciences3(6):721730.

Osborne SL, Riedell WE (2006). Soybean growth response to low rates of nitrogen applied at planting in the northern great plains. Journal of Plant Nutrition 29(6):985-1002.

PangLD, Wei-Jun LI, Zhu JZ, University XA (2015). Effects of carbon and nitrogen metabolism and the seed yield of Sudan grass under different topdressingnitrogen fertilizers. Acta AgrestiaSinica 23(1):180-186.

Phang TH, Shao G, Lam HM (2008). Salt tolerance in soybean. Journal of Integrative Plant Biology 50(10):1196-1212.

Prasanna BM, ArausJL, CrossaJ, CairnsJE, Palacios N, Das B (2013). High- 
throughput and precision phenotyping for cereal breeding programs. In: Cereal genomics II, Springer, Dordrecht pp 341-374.

Quain MD, Makgopa ME, Cooper JW, Kunert KJ, Foyer CH (2015). Ectopic phytocystatin expression increases nodule numbers and influences the responses of soybean (Glycine max) to nitrogen deficiency.Phytochemistry 112(1):179-187.

Ren C, Liu J, Gong Q (2014). Functions of autophagy in plant carbon and nitrogen metabolism. Frontiers in Plant Science 5:301.

Robin P (1979). Etude de quelques conditions d'extraction de la nitrate reductase des racines et des feuilles de plantules de mass. No. $79-463276$ CIMMYT

Shah JM, Asgher Z, ZengJ, Quan X, Ali E, Shamsi IH (2017). Growth and physiological characterization of low nitrogen responses in Tibetan wild barley (Hordeum spontaneum) and cultivated barley (Hordeum vulgare). Journal of Plant Nutrition 40(6):861-868.

Shang Jie, Yin Xiaoyu (2016). Present situation and reduction of chemical fertilizer non-point source pollution in China [J]. Eco-Economy 232(05):196-199.

Shao S, Li M, YangD, ZhangJ, Shi L (2016). The physiological variations of adaptation mechaniam in Glycine soja seedlings under saline and alkaline stresses. Pakistan Journal of Botany 48:2183-2193.

Takehisa H, Sato Y, Antonio BA, Nagamura Y (2013). Global transcriptome profile of rice root in response to essential macronutrient deficiency.Plant Signaling\& Behavior 8(6):e24409.

Williamson JM (2011). The role of information and prices in the nitrogen fertilizer management decision: new evidence from the agricultural resource management survey. Journal of Agricultural and Resource
Economics 36:552-572.

Xue Z, Zhao S, Gao H, Sun S (2014). The salt resistance of wild soybean (Glycine soja Sieb. et Zucc. ZYD 03262) under $\mathrm{NaCl}$ stress is mainly determined by $\mathrm{Na}^{+}$distribution in the plant. Acta Physiologiae Plantarum 36(1):61-70.

Yu JL, Zhang L, Zhang ZH, Shu JB, Song HX, Guan CY (2015). The relationship of carbon-nitrogen metabolism between nitrogen efficiency and its characteristics of rape.Acta Agriculturae Boreali-Sinica 30(1):219-224.

Yu N, Hui-Hui D, Qing-Ming LI, Qing-Hua MI, Bin H, Xi-Zhen AI (2015). Effects of red and blue light quality on the metabolites and key enzyme activities of carbon-nitrogen metabolism in celery. Plant PhysiologyJournal 51(1):112-118.

Yu XZ, Zhang FZ (2012). Activities of nitrate reductase and glutamine synthetase in rice seedlings during cyanide metabolism. Journal of Hazardous Materials 225:190-194.

Zhang ZL, Qu W (2004). Experimental guidance of plant physiology. Higher Education Press: Beijing.

Zhao MH, Sun J, Wang JY, Xu H, Tang L, Chen WF (2011). Global genome expression analysis of photosynthesis-related genes under low nitrogen stress in rice flagleaf. Scientia Agricultura Sinica 44(1):1-8.

Zhao X, Wang W, Xie Z, Gao Y, Wang C, Rashid MM (2018). Comparative analysis of metabolite changes in two contrasting rice genotypes in response to low-nitrogen stress. The Crop Journal 6(5):464474. 